\title{
Target Identification of MicroRNAs Expressed Highly and Regulated by Activin A in Human Embryonic Stem Cells
}

\author{
Steven Shoei-Lung Li \\ Kaohsiung Medical University \\ Taiwan
}

\section{Introduction}

Since 1998, when the first human embryonic stem (hES) cell lines were reported (Thomson et al., 1998), a large number of hES cell lines have been derived from the inner cell mass of preimplantation embryos donated at in vitro fertilization (IVF) clinics (Guhr et al., 2006). These hES cell lines possess remarkable ability of both unlimited self-renewal and pluripotency to generate any cell type differentiated from three germ-layers ectoderm, mesoderm and endoderm. Thus, these hES cell lines have great potentials for cell therapies in regenerative medicine and experimental models for drug discovery and toxicity testing in addition to basic studies on stem cell biology and molecular embryogenesis (Wobus \& Boheler, 2005).

The proliferation of undifferentiated hES cells can be maintained on either mitotically inactivated mouse embryonic fibroblasts (MEF) as feeder or Matrigel-coated plastic surfaces in MEF-conditioned medium (Xu et al., 2001). The continuous culture of undifferentiated hES cells either on MEF feeder or in the MEF-conditioned medium bears the risk of transmitting animal pathogens, and limits future medical applications of hES cells. A few human cell systems, including hES-derived fibroblast-like cells as feeder (Stojkovic et al., 2005), with capacity to support the growth of undifferentiated hES cells have been developed to replace the use of MEF. Activin A was previously reported to be necessary and sufficient for the maintenance of self-renewal and pluripotency of hES cells in long-term feeder- and serum-free culture (Xiao et al., 2006). It would be of interest to compare the gene expression profiles of these undifferentiated hES cells grown under these different conditions in order to better understand their common molecular mechanisms of unlimited self-renewal and pluripotency.

The genome-wide gene expression analyses using high-throughput microarray have been used to identify key "stemness" genes responsible for the unlimited self-renewal and pluripotency of hES cells (Ivanova et al., 2002; Ramalho-Santos et al., 2002; Sperger et al., 2003). A meta-analysis of 20 previously reported transcriptomes had identified 48 genes overexpressed in hES cells compared to differentiated cell types (Assou et al., 2007), and these 48 genes, including transcription factors such as OCT4 (also known as POU5F1), SOX2 and NANOG, may be responsible for the unlimited self-renewal and pluripotency of hES cells. However, molecular mechanisms involved in unlimited self-renewal and pluripotency of hES cells remain to be fully understood. 
Recently, microRNAs (miRNAs) have been shown to play important roles in mammalian embryo development and cell differentiation. Mammalian genomes encode many hundreds of miRNAs, which are predicted to regulate expression of as many as $30 \%$ of protein-coding genes (Bartel, 2004; Griffiths-Jones et al., 2006; John et al., 2004; Landgraf et al., 2007). Although the biological functions of most miRNAs are unknown, some miRNAs appear to participate in determination of cell fate, in pattern formation in embryonic development, and in control of cell proliferation, cell differentiation and cell apoptosis in animals (Alvarez-Garcia \& Miska, 2005; Kloosterman \& Plasterk, 2006). The miRNAs negatively regulate the posttranscriptional expression by translational repression and/or destabilization of protein-coding mRNAs. The impact of miRNAs on protein output was recently shown that although some targets were repressed without detectable changes in mRNA levels, those translationally repressed by more than a third also displayed detectable mRNA destabilization, and, for the more highly repressed targets, mRNA destabilization usually comprised the major component of repression (Baek et al., 2008; Selbach et al., 2008). In human and mouse, several ES cell-specific miRNAs were identified (Houbaviy et al., 2003; Laurent et al., 2008; Suh et al., 2004), and these miRNAs were shown to play crucial roles in ES cell differentiation, lineage specification, and organogenesis, especially neurogenesis and cardiogenesis (Chen et al., 2007). It would be important to identify the target mRNAs of hES cell-specific miRNAs that will lead us to understand the complex and interesting networks of regulation in hES cells.

In my laboratory at Kaohsiung Medical University in Taiwan, five hES cell lines have been derived with institutional review board approval from preimplantation embryos donated at in vitro fertilization clinics in Taiwan ( $\mathrm{Li}$ et al., 2006), and these lines have since been continuously cultured on mitotically inactivated MEF feeder in the hES medium for more than 44 passages and underwent freezing/thawing processes. All of five hES cell lines expressed characteristic undifferentiated hES markers such as SSEA-4, TRA-1-81, alkaline phosphatase, TERT, transcription factors POU5F1 (OCT4) and NANOG. The hES cell lines $\mathrm{T} 1$ and $\mathrm{T} 3$ possess normal female karyotypes, whereas lines T4 and T5 are normal male, but line $\mathrm{T} 2$ is male trisomy $12(47 \mathrm{XY},+12)$. The hES cell lines $\mathrm{T} 1, \mathrm{~T} 2, \mathrm{~T} 3$ and $\mathrm{T} 5$ were able to produce teratomas in SCID mice, and line T4 could only form embryoid bodies in vitro. Global gene expression profiling of these five hES cell lines indicated that the TGF $\beta /$ activin branch components inhibin BC, ACVR2A, ACVR1 (ALK2), TGFBR1 (ALK5) and SMAD2 were found to be highly expressed in undifferentiated states of these five hES cell lines and decreased upon differentiation. These hES cell lines are useful for drug development and toxicity testing in addition to basic studies on human stem cell biology.

\section{Target identification of hES cell-specific miRNAs}

The undifferentiated state of hES-T3 cells grown on MEF feeder layer was indicated by positive staining of OCT4 and NANOG, and these undifferentiated hES-T3 cells were designated as T3MF. An autogeneic feeder cells with capacity to support the growth of undifferentiated hES cells was established according to the previously published procedure (Stojkovic et al., 2005). hES-T3 (passage 19) cells were transferred into feeder-free and noncoated plate $(10 \mathrm{~cm})$ in DMEM supplemented with $10 \% \mathrm{FBS}$ under $5 \% \mathrm{CO}_{2}$ at $37{ }^{\circ} \mathrm{C}$. After 10 days, cells appeared as fibroblast-like morphology, that is, flat cells with elongated nucleus and branching pseudopodia, and these differentiated fibroblast-like cells are designated as T3DF. These T3DF cells were passaged using trypsin $(0.05 \%)$ every 4 days or 
cryopreserved. After inactivation using mitomycin C (10 ug/ml), T3DF cells (passage 8) as feeder have been shown to support the undifferentiated growth of hES-T3 cells for more than 14 passages, and the hES-T3 colonies grown on T3DF feeder were stained positively for OCT4 and NANOG [Li et al. 2009].

The expression profiles of 250 human miRNAs in T3MF and T3DF cells were quantitated using TagMan MicroRNA Assays as described previously (Chen et al., 2005; Liang et al., 2007; Li et al., 2009), and the expression level of each miRNA was indicated as folds over U6 snRNA. The four hES cell-specific miRNAs miR-302d, miR-367, miR-372 and miR-200c were found to express abundantly (more than 20-fold U6 snRNA) in T3MF cells, but little (0.03fold U6 snRNA) in T3DF cells (Table 1). These four miRNAs were also reported to be upregulated in hES cells (Laurent et al., 2008).

The genome-wide mRNA expression of T3MF and T3DF cells was determined using Affymetrix human genome U133 plus 2.0 GeneChip (Li et al., 2009). The original data had been deposited to NCBI database, and the GEO series number is GSE9440. The most expressed genes of T3MF cells include the undifferentiated hES markers such as OCT4, SOX2 and NANOG, and many of the most expressed mRNAs of T3MF cells were found to be in common with the 48 over-expressed genes in undifferentiated hES cells reported previously (Assou et al., 2007). The most expressed genes of differentiated T3DF cells include genes TRPS1, KLF13, MBNL2, MTMR3, NF1B, RAB6A, MARCKS, DDEF1, MBNL1 and QKI, which were later identified to be targets of four ES cell-specific miRNAs miR-302d, miR-372, miR-200c and/or miR-367 (Table 2).

\begin{tabular}{lrrrll}
\hline & & \multicolumn{3}{c}{ T3MF/ } & \\
miRNAs & T3MF & T3DF & T3DF & Specificity & Chromosome \\
\hline hsa-miR-302d & 204.60 & 0.01 & 20460 & hES & $4 \mathrm{q} 25$ \\
hsa-miR-367 & 136.40 & 0.01 & 13640 & hES & $4 \mathrm{q} 25$ \\
hsa-miR-372 & 27.80 & 0.01 & 2780 & hES & $19 \mathrm{q} 13.42$ \\
hsa-miR-200c & 27.73 & 0.03 & 937 & hES & $12 \mathrm{p} 13.31$ \\
hsa-miR-20b & 44.68 & 0.06 & 791 & & Xq26.2 \\
hsa-miR-26b & 24.02 & 0.07 & 349 & & $2 \mathrm{q} 35$ \\
hsa-miR-302c* & 13.82 & 0.01 & 1382 & hES & $4 \mathrm{q} 25$ \\
hsa-miR-302a* & 1.29 & 0.01 & 129 & hES & $4 \mathrm{q} 25$ \\
hsa-miR-302b* & 0.11 & 0.01 & 11 & hES & $4 \mathrm{q} 25$ \\
hsa-miR-371 & 3.25 & 0.01 & 325 & hES & $19 \mathrm{q} 13.42$ \\
hsa-miR-373* & 0.21 & 0.01 & 21 & hES & $19 \mathrm{q} 13.42$ \\
hsa-miR-368 & 0.01 & 0.01 & 1 & hES & $14 \mathrm{q} 32.31$ \\
\hline
\end{tabular}

Table 1. Expression levels of hES cell-specific miRNAs in T3ES and T3DF cells. This table is modified from Li et al. (2009).

The targets of the four hES cell-specific miRNAs miR-302d, miR-367, miR-372 and miR-200c miRNAs in hES cells are not known previously (Griffiths-Jones et al., 2006; John et al., 2004; Landgraf et al., 2007), and their potential targets were predicted using the methods of PicTar and TargetScanS (Sethupathy et al., 2006). The expression levels of these predicted target mRNAs in T3MF and T3DF cells were analyzed by the Volcano plot, and the differentially expressed genes were defined by more than 3-folds of changes (T3DF/T3MF) and a p-value cutoff of 0.05 . The 58 differentially expressed genes were found to express more than 3 -folds 


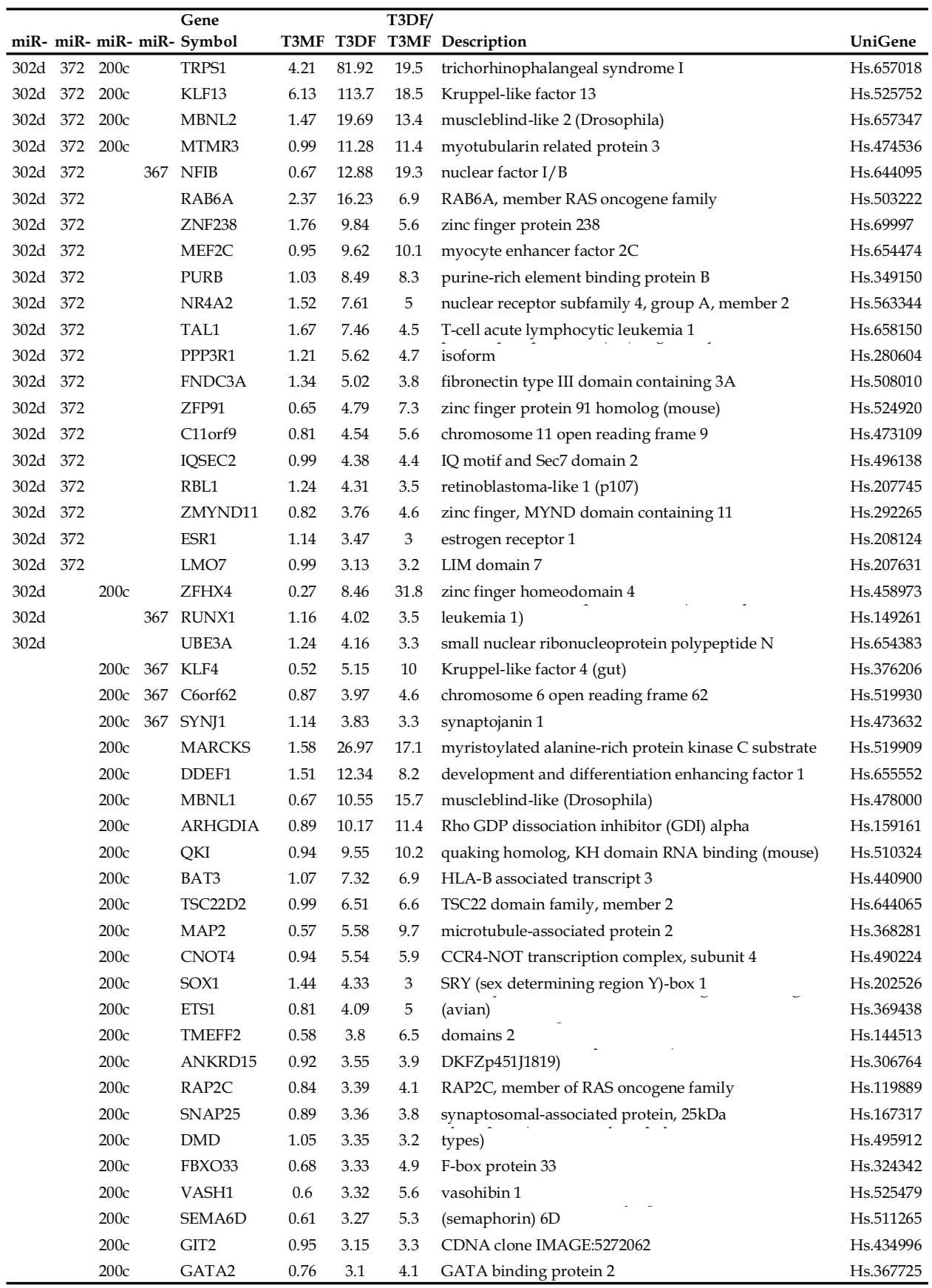

Table 2. Expression levels of 58 target mRNAs predicted by four miRNAs. This table is modified from Li et al. (2009). 
Target Identification of MicroRNAs Expressed Highly

\begin{tabular}{|c|c|c|c|c|c|c|}
\hline & Gene & & & T3DF/ & & \\
\hline miR- miR- miR- miR- & Symbol & T3MF & T3DF & T3MF & Description & UniGene \\
\hline 367 & SMAD6 & 1.5 & 6.23 & 4.1 & SMAD family member 6 & Hs.153863 \\
\hline 367 & CPEB4 & 0.56 & 4.76 & 8.6 & cytoplasmic polyadenylation element binding protein 4 & Hs.127126 \\
\hline 367 & WWP2 & 1.08 & 4.28 & 4 & WW domain containing E3 ubiquitin protein ligase 2 & Hs. 408458 \\
\hline 367 & CACNA1C & 0.97 & 4.2 & 4.3 & subunit & Hs.118262 \\
\hline 367 & TEF & 0.73 & 4.16 & 5.7 & thyrotrophic embryonic factor & Hs.181159 \\
\hline 367 & FMR1 & 0.98 & 4.05 & 4.1 & fragile $X$ mental retardation 1 & Hs.103183 \\
\hline 367 & DNAJB12 & 0.87 & 4.02 & 4.6 & DnaJ (Hsp40) homolog, subfamily B, member 12 & Hs.696014 \\
\hline 367 & ZNF287 & 1.05 & 3.81 & 3.6 & zinc finger protein 287 & Hs.99724 \\
\hline 367 & HAS3 & 1.15 & 3.79 & 3.3 & hyaluronan synthase 3 isoform $b$ & Hs.592069 \\
\hline 367 & ATXN3 & 1.12 & 3.48 & 3.1 & ataxin 3 & Hs.532632 \\
\hline
\end{tabular}

Table 2. continued.

of overall mean in T3DF cells (Table 2). Therefore, these 58 abundantly differentially expressed mRNAs are very likely to be the targets of four abundantly expressed miRNAs miR-302d, miR-372, miR-200c and/or miR-367 in hES cells (Li et al. 2009). Recently, 253 target mRNAs of mouse miR-290 cluster (corresponding to human miR-302 cluster) were found by the transcriptome analysis of ES cells lacking Dicer of miRNA processing enzyme (Sinkkonen et al., 2008). A comparison of these mouse 253 targets with the 58 targets of human miR-302d, miR-367, miR-372 and/or miR-200c revealed four common targets TRPS1, MBNL1, MBNL2 and NF1B.

The three genes TRPS1, KLF13 and MBNL2 were found to express extremely abundantly (more than 20-fold overall mean) in T3DF cells in which miR-302d, miR-372 and miR-200c had almost no expression (Tables 1 and 2), whereas these three genes TRPS1, KLF13 and MBNL2 exhibited relatively low mRNA expression in T3MF cells in which miR-302d, miR372 and miR-200c were expressed abundantly (more than 20-fold U6 snRNA). Therefore, the TRPS1, KLF13 and MBNL2 genes are very likely to be the common targets of three abundantly expressed miRNAs miR-302d, miR-372 and miR-200c in hES cells. To demonstrate directly whether TRPS1, KLF13 and MBNL2 were indeed the targets of miR$302 \mathrm{~d}$ and miR-372, the luciferase reporter vectors harboring the amplified 3'UTR fragments of target genes were cotransfected with and without miRNA precursor of either miR-302d or miR-372 in HEK293T cells (Li et al., 2009). The potential binding structures of the 3'UTR of TRPS1, KLF13 and MBNL2 genes by miRNAs miR-302d and miR-372 were predicted using PicTar program. The base-pairings between miRNAs and their targets, as well as the constructions of luciferase reporter vectors, were shown in Fig. 1A and B. The miR-302d specifically suppressed the luciferase activity to 57,62 and $80 \%$ of reporter vector harboring TRPS1, KLF13 and MBNL2, respectively. The miR-372 inhibited the luciferase activity to 86, 37 and $47 \%$ for TRPS1, KLF13 and MBNL2, respectively (Fig. 1C). These results implied that miR-302d and miR-372 were able to regulate negatively the same targets due to their same seed sequence. Furthermore, in order to confirm the predicted miRNA binding sites, the 4bp mutations of miR-302d and miR-372 binding sites on KLF13 and MBNL2 genes were generated by site-directed mutagenesis. The results of these reporter assays showed that miR-302d and miR-372 were indeed able to suppress specifically the luciferase activities of the reporter vectors harboring the predicted binding sites of wild-type 3'UTR of KLF13 and MBNL2, but not mutant-types (Fig. 1D).

The GeneOntology of the 58 abundantly differentially expressed targets by hES cell-specific miRNAs miR-302d, miR-372, miR-200c and/or miR-367 was analyzed (Li et al., 2009). 48 


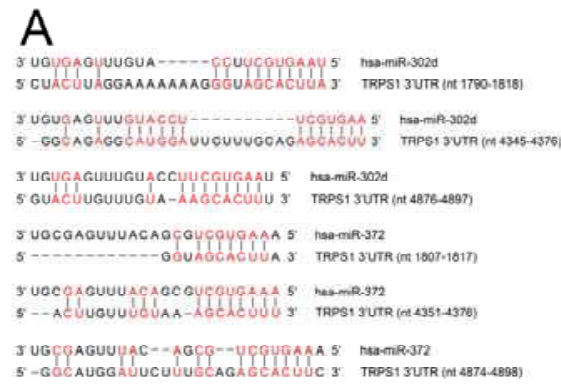

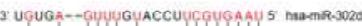

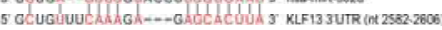

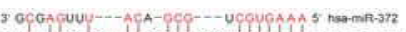

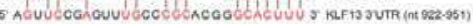

3 GCGA-GUUUACAG-CG-.-...--UCGUGAAA 5 mamR-372

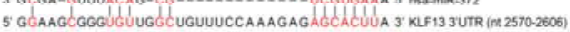

B

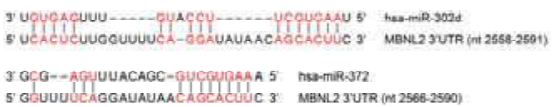

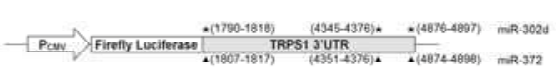

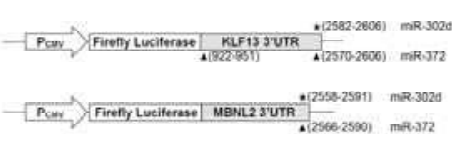

C
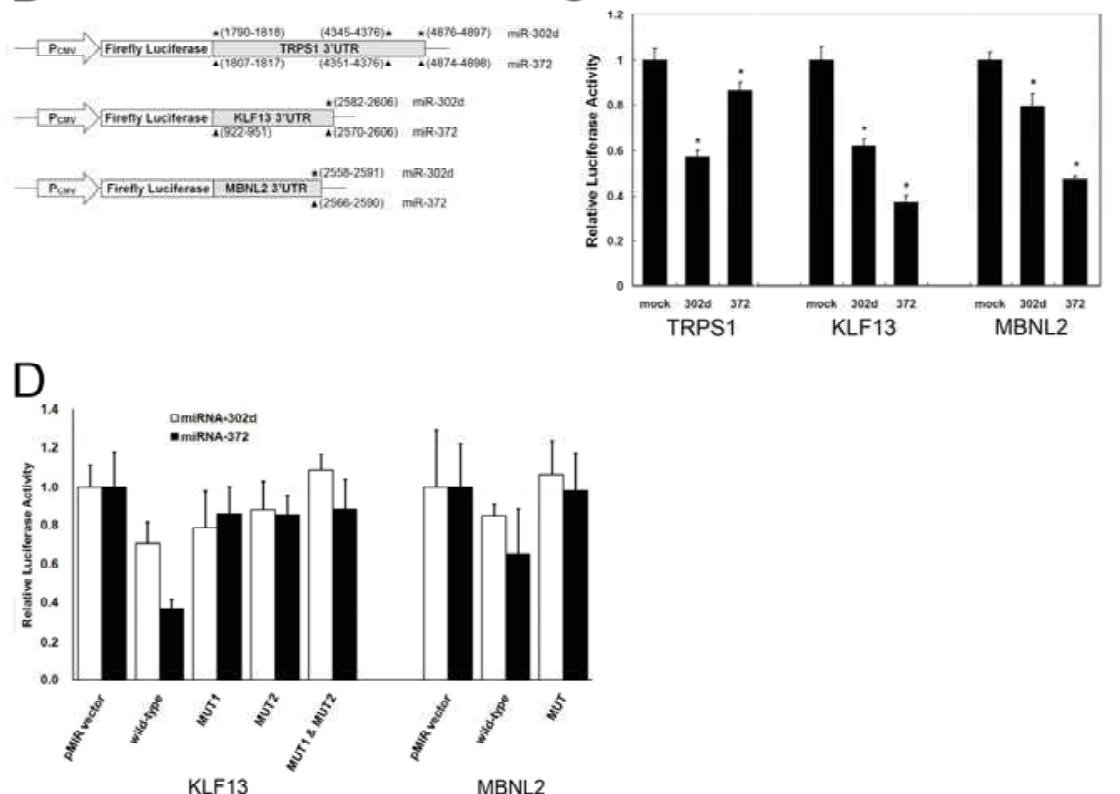

Fig. 1. TRPS1, KLF13 and MBNL2 targets of miR-302d and miR-372.

(A) Predicted binding sites of miR-302d and miR-372 within the 3'UTRs of TRPS1, KLF13 and MBNL2. (B) The construction of luciferase reporter vectors. (C) The effects of miR-302d and miR-372 on the luciferase activity of TRPS1, KLF13 and MBNL2 reporter vectors. (D) The effects of miR-302d and miR-372 on the luciferase activity of reporter vectors containing wild-type and mutant 3'UTRs of KLF13 and MBNL2 .

This figure is adapted from Li et al. (2009).

(p-value of 6.09E-10) of these 58 targets are localized in nucleus, and 39 (p-value of 4.38E-10) of them are involved in regulation of gene expression processes. The molecular functions of the 58 targets of four miRNAs expressed abundantly in hES cells were analyzed using GeneSpring GeneOntology Browser and MetaCore Analytical Suite. The top four molecular functions of eight categories obtained by GeneSpring were found to be the same to the top four molecular functions of eight categories obtained by MetaCore (Table 3). All of the top four molecular 
functions are involved in gene transcription. Among the other different categories between GeneSpring and MetaCore, zinc ion binding and sequence- specific DNA binding are also involved in gene transcription. In other words, the molecular functions of approximately half of these 58 targets are involved in gene transcription in hES cells.

\begin{tabular}{|c|c|c|c|c|}
\hline \multirow[b]{2}{*}{ Molecular functions } & \multicolumn{2}{|c|}{ GeneSpring } & \multicolumn{2}{|c|}{ MetaCore } \\
\hline & Genes & p-Value & Genes & p-Value \\
\hline Transcription factor activity & 18 & $1.03 \mathrm{E}-08$ & 28 & $8.87 \mathrm{E}-16$ \\
\hline Transcription regulator activity & 20 & 2.81E-07 & 30 & $1.40 \mathrm{E}-13$ \\
\hline Nucleic acid binding & 29 & $2.78 \mathrm{E}-06$ & 38 & $5.03 \mathrm{E}-10$ \\
\hline DNA binding & 22 & 1.80E-05 & 31 & 2.01E-09 \\
\hline Zinc ion binding & 19 & 0.000595 & & \\
\hline Calmodulin binding & 4 & 0.0039 & & \\
\hline Ciliary neurotrophic factor receptor binding & 1 & 0.00495 & & \\
\hline Calmodulin inhibitor activity & 1 & 0.00495 & & \\
\hline Protein N-terminus binding & & & 6 & $2.65 \mathrm{E}-07$ \\
\hline Estrogen receptor activity & & & 3 & 2.67E-07 \\
\hline Sequence-specific DNA binding & & & 12 & $1.91 \mathrm{E}-06$ \\
\hline Nitric-oxide synthase regulator activity & & & 3 & $5.53 \mathrm{E}-06$ \\
\hline
\end{tabular}

Table 3. Molecular functions of 58 abundantly differentially expressed targets.

This table is adapted from Li et al. (2009).

\section{Target identification of miRNAs up- and down-regulated by activin A}

The hES-T3 cells (passage 36) were cultured on the inactivated MEF feeder (designated as $\mathrm{T} 3 \mathrm{MF}$ ) in hES medium (containing $4 \mathrm{ng} / \mathrm{ml} \mathrm{bFGF}$ ) and feeder-free Matrigel in MEFconditioned medium with additional $4 \mathrm{ng} / \mathrm{ml}$ bFGF (designated as T3CM) for 14 and 12 more passages, respectively. The T3MF and T3CM cells were stained positively for OCT4 and NANOG, indicating that both T3MF and T3CM cell populations contained very high proportions of undifferentiated hES cells. When hES-T3 cells were grown on feeder-free Matrigel in hES medium (without bFGF) supplemented with 5, 10 and $25 \mathrm{ng} / \mathrm{ml}$ activin A, many cells around the edges, as well as the center, of colonies differentiated into fibroblastlike cells with much less staining of OCT4 and NANOG, and these cells were able to proliferate only two more passages, indicating that bFGF is indispensable for maintenance of self-renewal of hES cells. However, the hES cells cultured on feeder-free Matrigel in hES medium containing both $4 \mathrm{ng} / \mathrm{ml}$ bFGF and $5 \mathrm{ng} / \mathrm{ml}$ activin A (designated as T3BA) were able to proliferate for seven more passages, and most of these T3BA cells were stained positively for both OCT4 and NANOG (Tsai et al., 2010).

The genome-wide mRNA expression of T3MF, T3CM and T3BA cells was determined using Affymetrix human genome U133 plus 2.0 GeneChip (Tsai et al., 2010). The original data have been deposited to NCBI database, and the GEO series number is GSE16910. The average values of expressed mRNAs from T3MF, T3CM and T3BA cells were compared by scatter plots (Fig. 2A, B). The Pearson correlation coefficient of $\mathrm{R}^{2}=0.9934$ between T3MF and $\mathrm{T} 3 \mathrm{CM}$ cells indicates their very similar expression profiles of mRNAs (Fig. 2A), and only 49 and 17 genes were found to be abundantly (more than 3-folds of overall mean) 

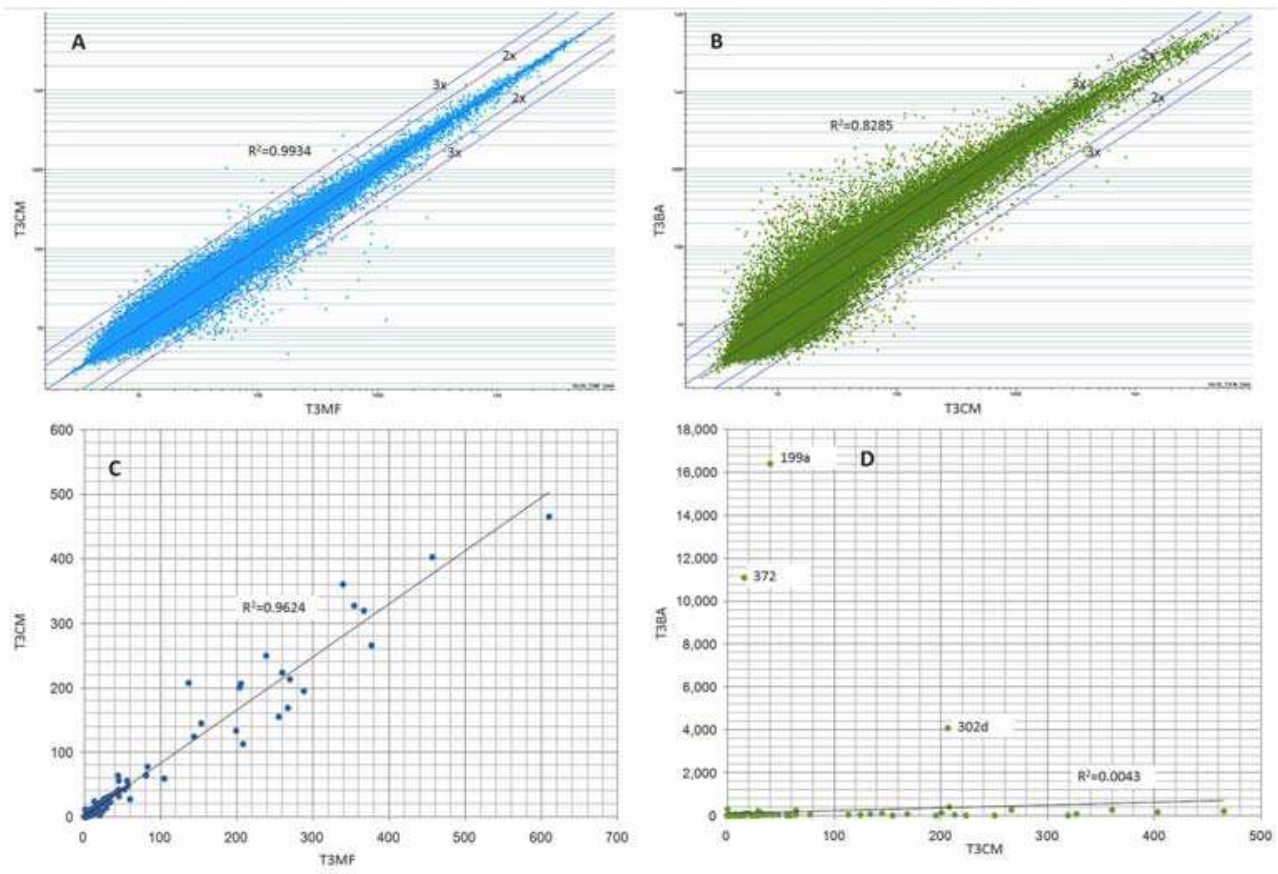

Fig. 2. Scatter plot and correlation analyses of mRNAs and miRNAs among T3MF, T3CM and T3BA cells.

(A) mRNAs of T3MF and T3CM; (B) mRNAs of T3BA and T3CM;

(C) miRNAs of T3MF and T3CM; (D) miRNAs of T3BA and T3CM.

This figure is adapted from Tsai et al. (2010).

differentially (more than 3-folds of changes) expressed in T3MF and T3CM cells, respectively. These results indicated that the unlimited self-renewal and pluripotency of hES-T3 cells can be maintained by continuous culture on either inactivated MEF feeder in hES medium (containing $4 \mathrm{ng} / \mathrm{ml} \mathrm{bFGF)} \mathrm{or} \mathrm{feeder-free} \mathrm{Matrigel} \mathrm{in} \mathrm{MEF-conditioned}$ medium (containing additional $4 \mathrm{ng} / \mathrm{ml} \mathrm{bFGF}$ ). The correlation value of $\mathrm{R}^{2}=0.8285$ between T3BA and T3CM cells suggests less similarity between their mRNA profiles (Fig. 2B), and 589 and 58 genes were abundantly differentially expressed in T3BA and T3CM cells, respectively.

The expression profiles of 250 human miRNAs in T3MF, T3CM and T3BA cells were quantitated using TaqMan microRNA Assays as described previously (Chen et al., 2005; Liang et al., 2007; Tsai et al., 2010), and the expression level of each miRNA was indicated as folds over U6 snRNA. The Pearson correlation coefficient of $\mathrm{R}^{2}=0.9624$ between T3MF and T3CM cells indicates their very similar miRNA expression profiles (Fig. 2C), while no correlation $\left(\mathrm{R}^{2}=0.0043\right)$ was found between T3BA and T3CM cells (Fig. 2D). When the three highly expressed miRNAs miR-199a, miR-372 and miR-302d were excluded from analysis, low correlation $\left(\mathrm{R}^{2}=0.3541\right)$ was still observed for the remaining 247 miRNAs of T3BA and T3CM cells. These results indicate that four hES cell-specific miRNAs miR-372, miR-302d, 
miR-367 and miR-200c, as well as three other miRNAs miR-199a, miR-217 and miR-19a, were over-expressed in T3BA cells, whereas five miRNAs miR-19b, miR-221, miR-222, let-7b and let-7c were under-expressed in T3BA cells compared with T3CM cells (Table 4).

\begin{tabular}{lcccccc}
\hline miRNAs & T3MF & T3CM & T3BA & T3CM & T3BA & Specificity \\
\hline A group (up-regulated) & & & & & & \\
hsa-miR-372 & 27.97 & 15.65 & 11079.38 & 707.9 & 0 & hES \\
hsa-miR-302d & 205.43 & 206.53 & 4071.21 & 19.7 & 0.1 & hES \\
hsa-miR-367 & 136.63 & 207.63 & 397.69 & 1.9 & 0.5 & hES \\
hsa-miR-200c & 27.76 & 28.94 & 201.26 & 7 & 0.1 & hES \\
hsa-miR-199a & 44.84 & 39.81 & 16380.51 & 411.5 & 0 & \\
hsa-miR-217 & 0.01 & 0.01 & 296.13 & 29613 & 0 & \\
hsa-miR-19a & 43.74 & 63.94 & 233.47 & 3.7 & 0.3 & \\
B group (down-regulated) & & & & & & \\
hsa-miR-19b & 366.63 & 319.07 & 2.56 & 0 & 124.6 & \\
hsa-miR-221 & 254.57 & 154.9 & 2.93 & 0 & 52.9 & \\
hsa-miR-222 & 287.47 & 195.53 & 6.73 & 0 & 29.1 & \\
hsa-let-7b & 259.6 & 223.2 & 12.12 & 0.1 & 18.4 & \\
hsa-let-7c & 237.9 & 250.27 & 15.17 & 0.1 & 16.5 & \\
\hline
\end{tabular}

Table 4. Levels of miRNAs expressed highly in T3MF, T3CM and T3BA cells This table is modified from Tsai et al. (2010).

\begin{tabular}{|c|c|c|c|c|c|c|c|}
\hline $\begin{array}{l}\text { Gene } \\
\text { Symbol } \\
\end{array}$ & $\begin{array}{c}\text { miR- } \\
372 \\
\end{array}$ & $302 d$ & 367 & $200 c$ & $19 a 199 a$ & 217 & Gene Description \\
\hline NR4A2 & 372 & $302 d$ & & & $19 \mathrm{a}$ & 217 & nuclear receptor subfamily 4 , group A, member 2 \\
\hline ERBB4 & 372 & $302 d$ & & & $19 \mathrm{a}$ & & v-erb-a erythroblastic leukemia viral oncogene homolog 4 \\
\hline CXCR4 & 372 & $302 d$ & & & & & chemokine (C-X-C motif) receptor 4 \\
\hline PCDH9 & & & 367 & & & & protocadherin 9 \\
\hline TMEFF2 & & & & $200 c$ & & & transmembrane protein with EGF- \& 2 follistatin-like dom 2 \\
\hline CD24 & & & & & $19 \mathrm{a}$ & & CD24 molecule \\
\hline COX6A1 & & & & & $199 \mathrm{a}$ & & cytochrome c oxidase subunit VIa polypeptide 1 \\
\hline TAL1 & 372 & $302 d$ & & & & & T-cell acute lymphocytic leukemia 1 \\
\hline GRIA3 & & & 367 & & & & glutamate receptor, ionotrophic, AMPA 3 \\
\hline PRDM1 & & & & $200 c$ & $19 a$ & & PR domain containing 1 , with ZNF domain \\
\hline MYT1 & & & & $200 c$ & $19 \mathrm{a}$ & & myelin transcription factor 1 \\
\hline EIF4G2 & & & & & $19 \mathrm{a}$ & & eukaryotic translation initiation factor 4 gamma, 2 \\
\hline CHMP4B & & & & & $19 \mathrm{a}$ & & chromatin modifying protein $4 \mathrm{~B}$ \\
\hline
\end{tabular}

Table 5. The 13 genes targeted by the activin A up-regulated miRNAs in T3BA cells. This table is modified from Tsai et al. (2010). 


\begin{tabular}{|c|c|c|c|c|c|c|}
\hline & miR- & & & let- & & \\
\hline Gene Symbol & $19 b$ & 221 & 222 & $7 \mathbf{b}$ & $7 \mathrm{c}$ & Gene Description \\
\hline ACTN1 & $19 \mathrm{~b}$ & & & & & actinin, alpha 1 \\
\hline ADRB2 & & & & $7 \mathrm{~b}$ & $7 \mathrm{c}$ & adrenergic, beta-2-, receptor, surface \\
\hline AMMECR1 & & & & & $7 \mathrm{c}$ & Alport syndrome, mental retardation, gene 1 \\
\hline AMT & & & & $7 \mathrm{~b}$ & & aminomethyltransferase \\
\hline ARFGEF1 & $19 b$ & & & & & ADP-ribosylation factor guanine nucleotide-exchange factor 1 \\
\hline ARIH2 & $19 \mathrm{~b}$ & & & & & ariadne homolog 2 (Drosophila) \\
\hline ATXN7L1 & $19 \mathrm{~b}$ & & & & & ataxin 7-like 1 \\
\hline CALB1 & & & & $7 \mathrm{~b}$ & $7 \mathrm{c}$ & calbindin $1,28 \mathrm{kDa}$ \\
\hline CCND2 & $19 \mathrm{~b}$ & & & $7 \mathrm{~b}$ & $7 \mathrm{c}$ & cyclin D2 \\
\hline CDC25A & & & & $7 \mathrm{~b}$ & $7 \mathrm{c}$ & cell division cycle 25 homolog A (S. pombe) \\
\hline CHD7 & & 221 & 222 & $7 \mathrm{~b}$ & $7 \mathrm{c}$ & chromodomain helicase DNA binding protein 7 \\
\hline CLASP2 & $19 b$ & & & $7 \mathrm{~b}$ & 7c & cytoplasmic linker associated protein 2 \\
\hline CLASP2 & $19 b$ & & & $7 \mathrm{~b}$ & $7 \mathrm{c}$ & cytoplasmic linker associated protein 2 \\
\hline COIL & & & & $7 \mathrm{~b}$ & $7 \mathrm{c}$ & coilin \\
\hline CPNE8 & & 221 & 222 & & & copine VIII \\
\hline DACH1 & & 221 & 222 & & & dachshund homolog 1 (Drosophila) \\
\hline DTNA & $19 \mathrm{~b}$ & & & & & dystrobrevin, alpha \\
\hline EFNB2 & $19 \mathrm{~b}$ & & & & & ephrin-B2 \\
\hline EIF2C1 & $19 b$ & & & $7 \mathrm{~b}$ & $7 \mathrm{c}$ & eukaryotic translation initiation factor $2 \mathrm{C}, 1$ \\
\hline FAM46B & $19 \mathrm{~b}$ & & & & & family with sequence similarity 46 , member B \\
\hline FIGN & $19 b$ & & & & $7 \mathrm{c}$ & fidgetin \\
\hline FRS2 & $19 b$ & 221 & & & & fibroblast growth factor receptor substrate 2 \\
\hline GRSF1 & $19 b$ & & & & & G-rich RNA sequence binding factor 1 \\
\hline GULP1 & $19 b$ & & & & & GULP, engulfment adaptor PTB domain containing 1 \\
\hline HIC2 & & & & $7 \mathrm{~b}$ & $7 \mathrm{c}$ & hypermethylated in cancer 2 \\
\hline ILF3 & $19 b$ & & & & & interleukin enhancer binding factor $3,90 \mathrm{kDa}$ \\
\hline KCMF1 & $19 \mathrm{~b}$ & 221 & 222 & & & potassium channel modulatory factor 1 \\
\hline KLF13 & $19 b$ & & & & & Kruppel-like factor 13 \\
\hline KRAS & $19 b$ & & & & & v-Ki-ras2 Kirsten rat sarcoma viral oncogene homolog \\
\hline MPPED2 & $19 b$ & & & & & metallophosphoesterase domain containing 2 \\
\hline MYCL1 & $19 b$ & & & & & v-myc myelocytomatosis viral oncogene homolog 1 , \\
\hline NAV3 & $19 b$ & & & & & neuron navigator 3 \\
\hline NRG1 & $19 \mathrm{~b}$ & & 222 & & & neuregulin 1 \\
\hline NRK & $19 \mathrm{~b}$ & 221 & 222 & $7 \mathrm{~b}$ & $7 \mathrm{c}$ & Nik related kinase \\
\hline PCDHA9 & $19 b$ & 221 & 222 & & & protocadherin alpha 9 \\
\hline PGM2L1 & & & & $7 \mathrm{~b}$ & $7 \mathrm{c}$ & phosphoglucomutase 2-like 1 \\
\hline POGZ & & 221 & 222 & $7 \mathrm{~b}$ & $7 \mathrm{c}$ & pogo transposable element with ZNF domain \\
\hline PRPF38B & & & & $7 \mathrm{~b}$ & $7 \mathrm{c}$ & PRP38 pre-mRNA processing factor 38 domain containing B \\
\hline PTBP2 & & 221 & & & & polypyrimidine tract binding protein 2 \\
\hline PTEN & & 221 & & & & phosphatase and tensin homolog \\
\hline RGS16 & & & & $7 \mathrm{~b}$ & $7 \mathrm{c}$ & regulator of G-protein signalling 16 \\
\hline SLC1A2 & $19 \mathrm{~b}$ & & 222 & & & solute carrier family 1 , member 2 \\
\hline SMARCD1 & & & & $7 \mathrm{~b}$ & $7 \mathrm{c}$ & SWI/SNF related, matrix associated, member 1 \\
\hline SOCS1 & $19 b$ & & & & & suppressor of cytokine signaling 1 \\
\hline SOX4 & $19 \mathrm{~b}$ & & 222 & & & SRY (sex determining region Y)-box 4 \\
\hline STRBP & & & & $7 \mathrm{~b}$ & $7 \mathrm{c}$ & spermatid perinuclear RNA binding protein \\
\hline VANGL2 & & & 222 & $7 \mathrm{~b}$ & & vang-like 2 (van gogh, Drosophila) \\
\hline VAV3 & $19 b$ & & & $7 \mathrm{~b}$ & $7 \mathrm{c}$ & vav 3 oncogene \\
\hline ZBTB10 & $19 b$ & & & $7 \mathrm{~b}$ & $7 \mathrm{c}$ & zinc finger and BTB domain containing 10 \\
\hline ZNF518 & & & & & & zinc finger protein 518 \\
\hline
\end{tabular}

Table 6 . The 50 genes targeted by the activin A down-regulated miRNAs This table is modified from Tsai et al. (2010). 
The potential targets of four abundantly expressed hES cell-specific miRNAs miR-372, miR302d, miR-367 and miR-200c, as well as three other over-expressed miRNAs miR-19a, miR199a and miR-217, were predicted by the PicTar (4-way) and TargetScanS with a cutoff $p$ value less than 0.05 . The expression levels of 13 target mRNAs were found to be inversed to their miRNAs (Tsai et al., 2010). Seven abundantly (more than 3-folds of overall mean) differentially (more than 3-folds of changes) expressed genes NR4A2, ERBB4, CXCR4, PCDH9, TMEFF2, CD24 and COX6A1, as well as six other genes TAL1, GRIA3, PRDM1, MYT1, EIF4G2 and CHMP4B, were found to be targets of miR-372, miR-302d, miR-367, miR200c, miR-19a, miR-199a and/or miR-217 (Table 5). It may be noted that the NR4A2, TMEFF2 and TAL1 were also included in the 58 target genes of hES cell-specific miR-372, miR-302d, miR-367 and/or miR-200c (Li et al., 2009). The five miRNAs miR-19b, miR-221, miR-222, let-7b and let-7c were under-expressed in T3BA cells compared with T3CM cells, and their 50 target mRNAs (Table 6) were also found to exhibit inverse expression levels (Tsai et al. 2010).

The two target genes NR4A2 and ERBB4 were chosen to be validated by luciferase assay, since they expressed abundantly (more than four folds of overall mean in T3CM cells) and highly differentially (more than 7-fold changes of T3CM/T3BA) (Table 5). The potential miRNA binding sites of the 3' UTRs of NR4A2 and ERBB4 genes were predicted using PicTar and TargetScanS programs. The 3' UTR of NR4A2 was found by both methods to contain two potential miR-372 binding sites, four miR-302d binding sites and one miR-19a binding site, but miR-217 binding site was predicted by TargetScanS only. The 3' UTR of ERBB4 was found by both methods to have one site for miR-302d and two sites for miR19a, but miR-372 binding site was predicted by TargetScanS only. The base-pairing between miRNAs and their target mRNAs, as well as the construction of luciferase reporter vectors, are shown in Fig. 3A, B. To demonstrate directly whether NR4A2 and ERBB4 genes were indeed the targets of miR-372, miR-302d, miR-19a and/or miR-217, the luciferase reporter vectors harboring the 3'UTRs of target genes were cotransfected with pSilencer vector containing miRNAs precursor or not in HEK293T cells (Tsai et al., 2010). The luciferase activity of reporter vector harboring NR4A2 3'UTR was inhibited to $37 \%, 38 \%, 53 \%$ or $33 \%$ by miR-372, miR-302d, miR-19a or miR-217, respectively. In the case of ERBB4, the luciferase activity was suppressed to $58 \%, 74 \%$ or $81 \%$ by miR-372, miR-302d or miR-19a, respectively (Fig. 3C). These results implied that NR4A2 gene was inhibited much stronger than ERBB4 gene by miR-372, miR-302d and miR-19a.

The mRNAs expressed more than three-folds of overall mean from T3BA and T3CM cells were also analyzed for the network and signaling pathways by using MetaCore Analytical Suite (Tsai et al., 2010). Besides 969 common genes, 1,396 and 153 genes were found to be unique for T3BA and T3CM cells, respectively (Fig. 4A), and the top 3 scored pathways (with lowest $\mathrm{p}$-value) involved in regulation of cell cycle were highly regulated by activin $\mathrm{A}$ (Fig. 4B). Activin A has been reported to inhibit cell proliferation and activate cell differentiation, although it was also shown to participate in maintenance of pluripotency (Beattie et al., 2005; James et al., 2005). Activin A through its receptor ActR2B increased the expression of OCT4 and NANOG, as well as LEFTY-1 and LEFTY-2, to regulate stem cell maintenance. The abundantly differentially expressed target genes NR4A2, ERBB4 and CXCR4 of miRNAs miR-372, miR-302d, miR-19a and/or miR-217 highly induced by activin $A$ in T3BA cells were further analyzed using IPA for their involvements in network and signaling pathways. The NR4A2 in nucleus and CXCR4 associated with plasma membrane 
A

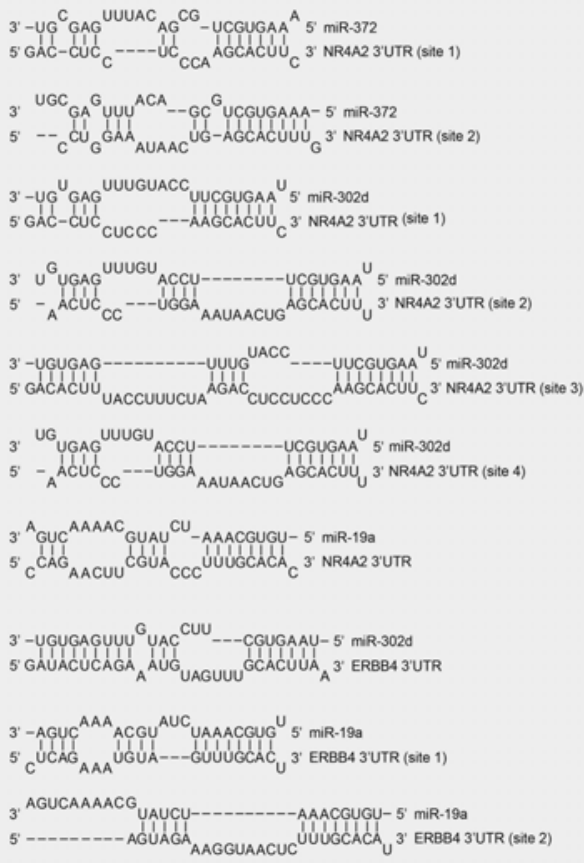

B

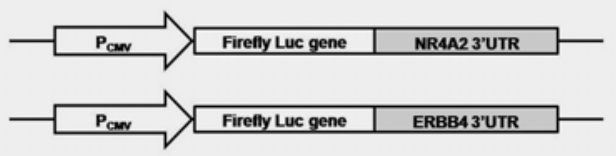

C

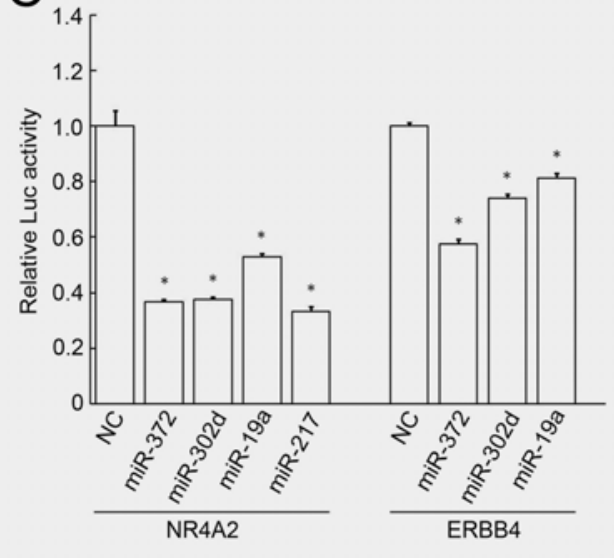

Fig. 3. Leuciferase experiments to validate NR4A2 and ERBB4 targets

(A) Predicted binding sites of miR-372, miR-302d and miR-19a within the 3'UTRs of NR4A2 and ERBB4. (B) The construction of luciferase reporter vectors. (C) The effects of miR-372, miR-302d, miR-19a and/or miR-217 on the luciferase activity of NR4A2 and ERBB4 reporter vectors.

This figure is adapted from Tsai et al. (2010).

were found to be commonly regulated by both EGF and TNF, while the membrane associated ERBB4 is regulated by EGF only. The NR4A2, also known as NURR1, is essential for the differentiation of the midbrain dopaminergic neurons, and it was reported to cooperate with PITX3 in promoting the terminal maturation of human and murine embryonic stem cell cultures to a dopamine neuron phenotype, and neither factor alone induced differentiation (Martinat et al., 2006). The ERBB4 is a transmembrane receptor tyrosine kinase that regulates cell proliferation and differentiation. The ERBB4 and its ligand heregulin are essential for neuronal development. The ERBB4 was reported to express at high levels in rat subventricular zone and rostral migatory system and to play a role in neuroblast tangential migration and olfactory interneuronal placement (Anton et al., 2004). The CXCR4, a chemokine receptor, is a crucial effector of the transcriptional pathway specifying mouse ventral motor neurons, and it controls the precision of initial motor axon trajectories (Lieberam et al., 2005). The CXCR4 has also been used as a biomarker of definite endoderm which is induced by activin A. 


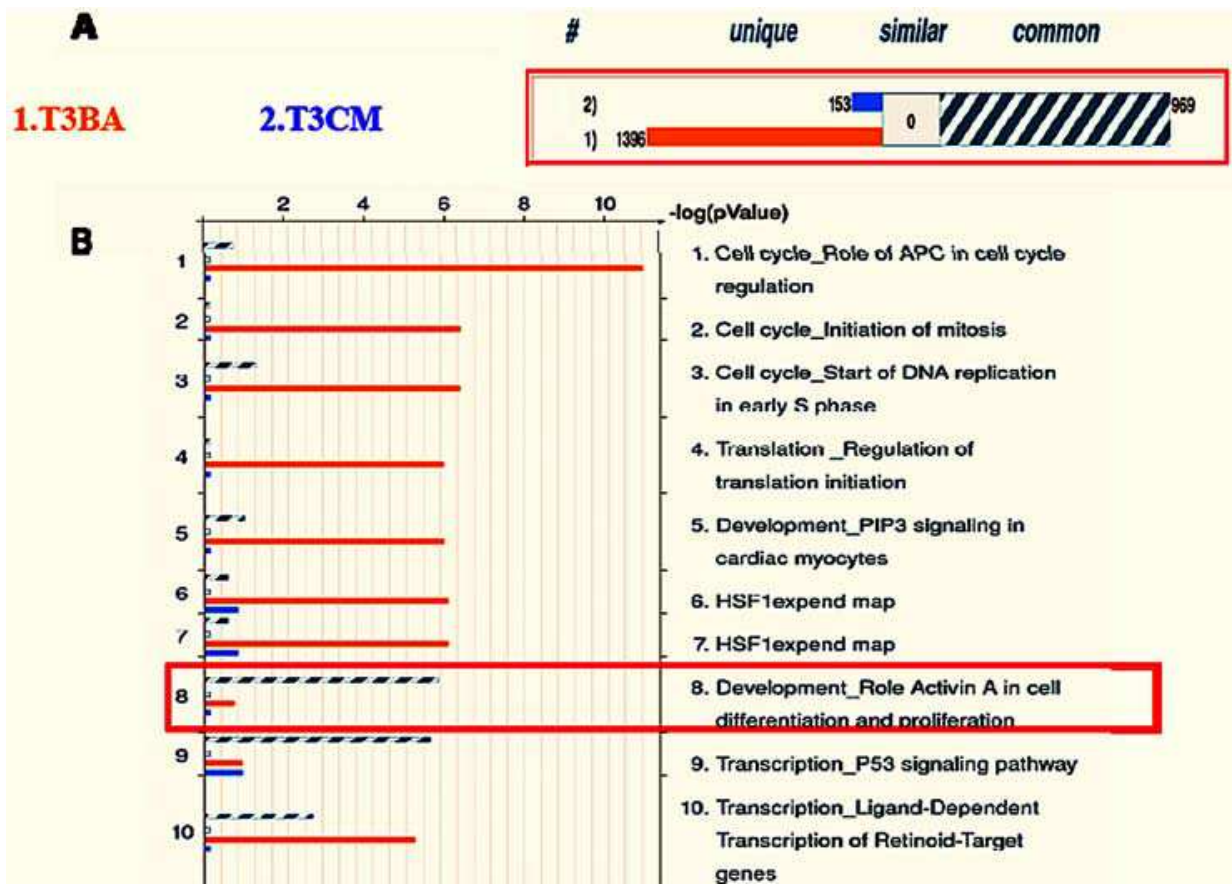

Fig. 4. Comparison of gene expression and GeneGo canonical pathway maps among T3CM and T3BA cells.

(A) The parameters for comparison are set at threshold of 3 with p-value of 0.05 . The common genes are indicated by blue/white strips. The unique genes are marked as color band: (1) T3BA, orange; (2) T3CM, blue. (B) The top 10 GeneGo canonical pathway maps among T3BA and T3CM cells. The degree of "relevance" to different GeneGo ontology categories is defined by p-value, so that the lower random p-value gets higher priority. This figure is adapted from Tsai et al. (2010).

The seven miRNAs miR-372, miR-302d, miR-367, miR-200c, miR-19a, miR-199a and miR-217 were found to be highly up-regulated by activin A in T3BA cells (Table 4 and Fig. 2D). The expression of hES cell-specific miR-302 cluster was previously shown to be regulated by OCT4 and SOX2 (Card et al., 2008). Thus, activin A through its receptor ActR2B increased indirectly the expression of OCT4 to induce the expression of hES cell-specific miR-372, miR-302d, miR-367 and miR-200c. The miR-199a was found to be most abundant in T3BA cells, and its target COX6A1 expressed extremely abundantly in T3MF and T3CM cells was down-regulated inT3BA cells. The miR-199a is encoded by duplicated genes located within the intron of dynamin genes on chromosomes 1 and 19. Since the miR-199a genes are 
positioned in opposite direction to the dynamin genes, they may be transcribed from their own promoters. The expression of miR-199a was also reported to be controlled by transcription factor TWIST-1 via an E-box promoter element (Lee et al., 2009), and how activin A indirectly regulate TWIST-1 remains to be elucidated. It may be noted that miR199a and miR-199a* (processed from the same miRNA precursor) were recently reported to down-regulate the MET proto-oncogene and its downstream effector extracellular signalregulated kinase 2 (ERK2) gene resulting in inhibiting cell proliferation of tumor cells (Kim et al., 2008). The miR-199a and miR-199a* were also shown to inhibit the mRNA translation of $\mathrm{I} \kappa \mathrm{B}$ kinase $\beta$ required for NF- $\mathrm{kB}$ activation in ovarian cancer cells (Chen et al., 2008). The miR-217 was also found to be highly expressed in T3BA, but not at all in T3MF and T3CM cells (Table 4). It is of interest that the miR-217 was reported to be linked to tumorigenesis in pancreatic ductal adenocarcinoma (Szafranska et al., 2007) and used as one of biomarkers to discriminate benign and malignant pancreatic tissues (Szafranska et al., 2008).

\section{Conclusions}

The hES-T3 cells with normal female karyotype, one of five hES cell lines derived in my laboratory in Taiwan, were maintained their undifferentiated growth on the inactivated MEF feeder (T3MF), in MEF-conditioned medium (T3CM) and hES medium supplemented with both bFGF and activin A (T3BA). Autogeneic feeder fibroblast (T3DF) cells with capacity to support the undifferentiated growth of hES cells were spontaneously differentiated from hES-T3 cells. The expression profiles of miRNAs and mRNAs from these four cell types (T3MF, T3CM, T3BA \& T3DF) were quantitatively determined, and many target mRNAs of miRNAs expressed highly and regulated by activin A in hES cells were identified by the inverse expression levels of miRNAs to their target mRNAs. Approximately half of the 58 targets by hES cell-specific miRNAs miR-372, miR-302d, miR367 and/or miR-200c were involved in gene transcription. Four hES cell-specific microRNAs miR-372, miR-302d, miR-367 and miR-200c, as well as three other microRNAs miR-199a, miR-19a and miR-217, were found to be up-regulated, whereas five miRNAs miR-19b, miR221, miR-222, let-7b and let-7c were down-regulated by activin A. Thirteen abundantly differentially expressed mRNAs, including NR4A2, ERBB4, CXCR4, PCDH9, TMEFF2, CD24 and COX6A1 genes, targeted by seven over-expressed miRNAs were identified. The NR4A2, ERBB4 and CXCR4 target genes were further found to be regulated by EGF and/or TNF. The 50 abundantly differentially expressed genes targeted by five under-expressed miRNAs were also identified. The abundantly expressed mRNAs were also analyzed for the network and signaling pathways, and roles of activin A in cell proliferation and differentiation were found. These findings will help elucidate the complex signaling networks which maintain the unlimited self-renewal and pluripotency of hES cells. The autogeneic fibroblasts derived from hES cells will be useful to reduce the risk of animal pathogens in the future medical applications of hES cells.

\section{Acknowledgements}

I thank Drs. P.-C. Yang, S.-L. Yu, S. Singh and Y.-H. Liu for their productive collaborations; Z.-Y. Tsai, L.-P. Kao , B.-Z. Chen and B.-C. Ho for their hard work; and M.P. Li for copy 
editing. The tables and figures are modified/adapted with permission from Li et al. (2009) and Tsai et al. (2010). My research has been supported by grants from National Science Council of Taiwan.

\section{References}

Alvarez-Garcia, I. \& Miska, E.A. (2005). MicroRNA functions in animal development and human disease. Development 132:4653-62.

Anton, E.S.; Ghashghaei, H.T.; Weber, J.L,; McCann, C.; Fischer, T.M.; Cheung, I.D.; Gassmann, M.; Messing, A.; Klein, R.; Schwab, M.H.; Lloyd, K.C. \& Lai, C. (2004) Receptor tyrosine kinase ErbB4 modulates neuroblast migration and placement in the adult forebrain. Nat Neurosci 7:1319-28.

Assou, S.; Le Carrour, T.; Tondeur, S.; Strom, S.; Gabelle, A.; Marty, S.; Nadal, L.; Pantesco, V.; Reme, T.; Hugnot, J.P.; Gasca, S.; Hovatta, O.; Hamamah, S.; Klein, B. \& De Vos, J. (2007) A meta-analysis of human embryonic stem cells transcriptome integrated into a web-based expression atlas. Stem Cells 25:961-73.

Baek, D.; Villen, J.; Shin, C.; Camargo, F.D.; Gygi, S.P \& Bartel, D.P. (2008) The impact of microRNAs on protein output. Nature 455:64-71.

Bartel, D.P. (2004) MicroRNAs: genomics, biogenesis, mechanism, and function. Cell 116:281-97.

Beattie, G.M.; Lopez, A.D.; Bucay, N.; Hinton, A.; Firpo, M.T.; King, C.C. \& Hayek, A. (2005) Activin A maintains pluripotency of human embryonic stem cells in the absence of feeder layers. Stem Cells 23:489-95.

Card, D.A.; Hebbar, P.B.; Li, L.; Trotter, K.W.; Komatsu, Y.; Mishina, Y. \& Archer. T.K. (2008) Oct4/Sox2-regulated miR-302 targets cyclin D1 in human embryonic stem cells. Mol Cell Biol 28:6426-38.

Chen, C.; Ridzon, D.A.; Broomer, A.J.; Zhou, Z.; Lee, D.H.; Nguyen, J.T.; Barbisin, M.; Xu, N.L.; Mahuvakar, V.R.; Andersen, M.R.; Lao, K.Q.; Livak, K.J. \& Guegler, K.J. (2005) Real-time quantification of microRNAs by stem-loop RT-PCR. Nucleic Acids Res 33:e179.

Chen, C.; Ridzon, D.; Lee, C.T.; Blake, J.; Sun, Y. \& Strauss, W.M. (2007) Defining embryonic stem cell identity using differentiation-related microRNAs and their potential targets. Mamm Genome 18:316-27.

Chen, R.; Alvero, A.B.; Silasi, D.A.; Kelly, M.G.; Fest, S.; Visintin, I.; Leiser, A.; Schwartz, P.E.; Rutherford, T. \& Mor, G. (2008) Regulation of IKKbeta by miR-199a affects NF-kappaB activity in ovarian cancer cells. Oncogene 27:4712-23.

Griffiths-Jones, S.; Grocock, R.J.; van Dongen, S.; Bateman, A. \& Enright, A.J. (2006) miRBase: microRNA sequences, targets and gene nomenclature. Nucleic Acids Res 34:D140-4.

Guhr, A.; Kurtz, A.; Friedgen, K. \& Loser, P. (2006) Current state of human embryonic stem cell research: an overview of cell lines and their use in experimental work. Stem Cells 24:2187-91.

Houbaviy, H.B.; Murray, M.F. \& Sharp, P.A. (2003) Embryonic stem cell-specific MicroRNAs. Dev Cell 5:351-8. 
Ivanova, N.B.; Dimos, J.T.; Schaniel, C.; Hackney, J.A.; Moore, K.A. \& Lemischka, I.R. (2002) A stem cell molecular signature. Science 298:601-4.

James, D.; Levine, A.J.; Besser, D. \& Hemmati-Brivanlou, A. (2005) TGFbeta/activin/nodal signaling is necessary for the maintenance of pluripotency in human embryonic stem cells. Development 132:1273-82.

John, B.; Enright, A.J.; Aravin, A.; Tuschl, T.; Sander, C. \& Marks, D.S. (2004) Human microRNA targets. PLoS Biol 2:e363.

Kim, S.; Lee, U.J.; Kim, M.N.; Lee, E.J.; Kim, J.Y.; Lee, M.Y.; Choung, S.; Kim, Y.J. \& Choi, Y.C. (2008) MicroRNA miR-199a* regulates the MET proto-oncogene and the downstream extracellular signal-regulated kinase 2 (ERK2). J Biol Chem 283:1815866.

Kloosterman, W.P. \& Plasterk, R.H. (2006) The diverse functions of microRNAs in animal development and disease. Dev Cell 11:441-50.

Landgraf, P.; Rusu, M.; Sheridan, R.; Sewer, A.; Iovino, N.; Aravin, A.; Pfeffer, S.; Rice, A.; Kamphorst, A.O.; Landthaler, M.; Lin, C.; Socci, N.D.; Hermida, L.; Fulci, V.; Chiaretti, S.; Foa, R.; Schliwka, J.; Fuchs, U.; Novosel, A.; Muller, R.U.; Schermer, B.; Bissels, U.; Inman, J.; Phan, Q.; Chien, M.; Weir, D.B.; Choksi, R.; De Vita, G.; Frezzetti, D.; Trompeter, H.I.; Hornung, V.; Teng, G.; Hartmann, G.; Palkovits, M.; Di Lauro, R.; Wernet, P.; Macino, G.; Rogler, C.E.; Nagle, J.W.; Ju, J.; Papavasiliou, F.N.; Benzing, T.; Lichter, P.; Tam, W.; Brownstein, M.J.; Bosio, A.; Borkhardt, A.; Russo, J.J.; Sander, C.; Zavolan, M. \& Tuschl, T. (2007) A mammalian microRNA expression atlas based on small RNA library sequencing. Cell 129:1401-14.

Laurent, L.C.; Chen, J.; Ulitsky, I.; Mueller, F.J.; Lu, C.; Shamir, R.; Fan, J.B. \& Loring, J.F. (2008) Comprehensive microRNA profiling reveals a unique human embryonic stem cell signature dominated by a single seed sequence. Stem Cells.

Lee, Y.B.; Bantounas, I.; Lee, D.Y.; Phylactou, L.; Caldwell, M.A. \& Uney, J.B. (2009) Twist-1 regulates the miR-199a/214 cluster during development. Nucleic Acids Res 37:1238.

Li, S.S.; Liu, Y.-H.; Tseng, C.-N.; Chung, T.-L.; Lee, T.-Y. \& Singh, S. (2006) Characterization and gene expression profiling of five new human embryonic stem cell lines derived in Taiwan. Stem Cells Dev. 15:532-55.

Li, S.S.; Yu, S.L.; Kao, L.P.; Tsai, Z.Y.; Singh, S.; Chen, B.Z.; Ho, B.C.; Liu, Y.H. \& Yang, P.C. (2009.) Target identification of microRNAs expressed highly in human embryonic stem cells. J Cell Biochem 106:1020-30.

Liang, Y.; Ridzon, D.; Wong, L. \& Chen, C. (2007) Characterization of microRNA expression profiles in normal human tissues. BMC Genomics 8:166.

Lieberam, I.; Agalliu, D.; Nagasawa, T.; Ericson, J. \& Jessell, T.M. (2005) A Cxcl12-CXCR4 chemokine signaling pathway defines the initial trajectory of mammalian motor axons. Neuron 47:667-79.

Martinat, C.; Bacci, J.J.; Leete, T.; Kim, J.; Vanti, W.B.; Newman, A.H.; Cha, J.H.; Gether, U.; Wang, H. \& Abeliovich, A. (2006) Cooperative transcription activation by Nurr1 and Pitx 3 induces embryonic stem cell maturation to the midbrain dopamine neuron phenotype. Proc Natl Acad Sci U S A 103:2874-9. 
Ramalho-Santos, M.; Yoon, S.; Matsuzaki, Y.; Mulligan, R.C. \& Melton, D.A. (2002) "Stemness": transcriptional profiling of embryonic and adult stem cells. Science 298:597-600.

Selbach, M.; Schwanhausser, B.; Thierfelder, N.; Fang, Z.; Khanin, R. \& Rajewsky, N. (2008) Widespread changes in protein synthesis induced by microRNAs. Nature 455:5863.

Sethupathy, P.; Megraw, M. \& Hatzigeorgiou, A.G. (2006) A guide through present computational approaches for the identification of mammalian microRNA targets. Nat Methods 3:881-6.

Sinkkonen, L.; Hugenschmidt, T.; Berninger, P.; Gaidatzis, D.; Mohn, F.; Artus-Revel, C.G.; Zavolan, M.; Svoboda, P. \& Filipowicz, W. (2008) MicroRNAs control de novo DNA methylation through regulation of transcriptional repressors in mouse embryonic stem cells. Nat Struct Mol Biol 15:259-67.

Sperger, J.M.; Chen, X.; Draper, J.S.; Antosiewicz, J.E.; Chon, C.H.; Jones, S.B.; Brooks, J.D.; Andrews, P.W.; Brown, P.O. \& Thomson, J.A. (2003) Gene expression patterns in human embryonic stem cells and human pluripotent germ cell tumors. Proc Natl Acad Sci U S A 100:13350-5.

Stojkovic, P.; Lako, M.; Stewart, R.; Przyborski, S.; Armstrong, L.; Evans, J.; Murdoch, A.; Strachan, T. \& Stojkovic, M. (2005) An autogeneic feeder cell system that efficiently supports growth of undifferentiated human embryonic stem cells. Stem Cells 23:306-14.

Suh, M.R.; Lee, Y.; Kim, J.Y.; Kim, S.K.; Moon, S.H.; Lee, J.Y.; Cha, K.Y.; Chung, H.M.; Yoon, H.S.; Moon, S.Y.; Kim, V.N. \& Kim, K.S. (2004) Human embryonic stem cells express a unique set of microRNAs. Dev Biol 270:488-98.

Szafranska, A.E.; Davison, T.S.; John, J.; Cannon, T.; Sipos, B.; Maghnouj, A.; Labourier, E. \& Hahn, S.A. (2007) MicroRNA expression alterations are linked to tumorigenesis and non-neoplastic processes in pancreatic ductal adenocarcinoma. Oncogene 26:444252.

Szafranska, A.E.; Doleshal, M.; Edmunds, H.S.; Gordon, S.; Luttges, J.; Munding, J.B.; Barth, R.J. Jr.; Gutmann, E.J.; Suriawinata, A.A.; Marc Pipas, J.; Tannapfel, A.; Korc, M.; Hahn, S.A.; Labourier, E. \& Tsongalis, G.J. (2008) Analysis of microRNAs in pancreatic fine-needle aspirates can classify benign and malignant tissues. Clin Chem 54:1716-24.

Thomson, J.A.; Itskovitz-Eldor, J.; Shapiro, S.S.; Waknitz, M.A.; Swiergiel, J.J.; Marshall, V.S. \& Jones, J.M. (1998) Embryonic stem cell lines derived from human blastocysts. Science 282:1145-7.

Tsai, Z.Y., Yu, S.-L.; Singh, S.; Kao, L.-P.; Chen, B.Z.; Yang, P.-C. \& Li. S.S. (2010) Identification of microRNAs regulated by activin A in human embryonic stem cells. J. Cell. Biochem. 109:93-102.

Wobus, A.M. \& Boheler, K.R. (2005) Embryonic stem cells: prospects for developmental biology and cell therapy. Physiol Rev 85:635-78.

Xiao, L.; Yuan, X. \& Sharkis, S.J. (2006) Activin A maintains self-renewal and regulates fibroblast growth factor, Wnt, and bone morphogenic protein pathways in human embryonic stem cells. Stem Cells 24:1476-86. 
Xu, C.; Inokuma, M.S.; Denham, J.; Golds, K.; Kundu, P.; Gold, J.D. \& Carpenter, M.K. (2001) Feeder-free growth of undifferentiated human embryonic stem cells. Nat Biotechnol 19:971-4. 


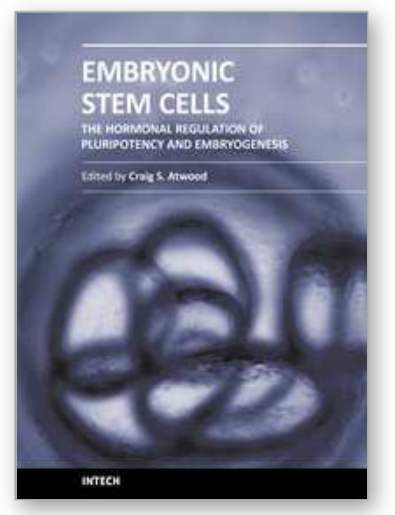

\section{Embryonic Stem Cells: The Hormonal Regulation of Pluripotency and Embryogenesis}

Edited by Prof. Craig Atwood

ISBN 978-953-307-196-1

Hard cover, 672 pages

Publisher InTech

Published online 26, April, 2011

Published in print edition April, 2011

Pluripotency is a prerequisite for the subsequent coordinated differentiation of embryonic stem cells into all tissues of the body. This book describes recent advances in our understanding of pluripotency and the hormonal regulation of embryonic stem cell differentiation into tissue types derived from the ectoderm, mesoderm and endoderm.

\section{How to reference}

In order to correctly reference this scholarly work, feel free to copy and paste the following:

Steven Shoei-Lung Li (2011). Target Identification of MicroRNAs Expressed Highly and Regulated by Activin A in Human Embryonic Stem Cells, Embryonic Stem Cells: The Hormonal Regulation of Pluripotency and Embryogenesis, Prof. Craig Atwood (Ed.), ISBN: 978-953-307-196-1, InTech, Available from: http://www.intechopen.com/books/embryonic-stem-cells-the-hormonal-regulation-of-pluripotency-andembryogenesis/target-identification-of-micrornas-expressed-highly-and-regulated-by-activin-a-in-humanembryonic-st

\section{INTECH}

open science | open minds

\section{InTech Europe}

University Campus STeP Ri

Slavka Krautzeka 83/A

51000 Rijeka, Croatia

Phone: +385 (51) 770447

Fax: +385 (51) 686166

www.intechopen.com

\section{InTech China}

Unit 405, Office Block, Hotel Equatorial Shanghai

No.65, Yan An Road (West), Shanghai, 200040, China

中国上海市延安西路65号上海国际贵都大饭店办公楼 405 单元

Phone: +86-21-62489820

Fax: +86-21-62489821 
(C) 2011 The Author(s). Licensee IntechOpen. This chapter is distributed under the terms of the Creative Commons Attribution-NonCommercialShareAlike-3.0 License, which permits use, distribution and reproduction for non-commercial purposes, provided the original is properly cited and derivative works building on this content are distributed under the same license. 